(KP) can improve health-related quality of life. In the Netherlands, the incidence of KPs and KP revisions has increased, but health care costs related to these procedures over time and their determinants are unknown. ${ }^{1}$

Objectives: To provide estimates of age and sex-specific incidence of KPs, revision KPs, and prosthesis complications in patients with knee OA. To determine average annual health care costs of patients undergoing KP compared with matched controls in the Netherlands, and to understand drivers of costs.

Methods: All KPs in knee OA patients in the Achmea Health Database were identified and matched by age, sex, and region to a maximum of four controls. Incidence rates of KPs, KP revisions, and their complications (/1000 persons) from 2006-2013 were determined. Annual health care cost and excess costs compared to matched controls, preceding, during and after surgery were calculated and associated factors evaluated using longitudinal regression analysis.

Results: The incidence of KPs, KP revisions, and complications increased between 2006 and 2013. This increase was strongest in younger age categories and in men (Table 1). Annual health care costs slightly increased up to the year of surgery, with highest costs in the year of surgery. Post-surgery costs remained slightly higher than pre-surgery costs. High post-surgery costs were mainly associated with subsequent KPs. Other factors associated with high excess costs were younger age, female gender, and complications.

Table 1. Sex-specific incidence rates (per 1,000 person years) of all KPs, KP revisions, and complications associated with knee OA

\begin{tabular}{lcccccccc}
\hline & $\begin{array}{c}2006 \\
\text { IR }\end{array}$ & $\begin{array}{c}2007 \\
\text { IR }\end{array}$ & $\begin{array}{c}2008 \\
\text { IR }\end{array}$ & $\begin{array}{c}2009 \\
\text { IR }\end{array}$ & $\begin{array}{c}2010 \\
\text { IR }\end{array}$ & $\begin{array}{c}2011 \\
\text { IR }\end{array}$ & $\begin{array}{c}2012 \\
\text { IR }\end{array}$ & $\begin{array}{c}2013 \\
\text { IR }\end{array}$ \\
\hline All KPs & & & & & & & & \\
Male & 0.81 & 0.86 & 1.04 & 1.04 & 1.11 & 1.19 & 1.26 & 1.26 \\
Female & 2.01 & 1.96 & 2.08 & 2.09 & 2.09 & 2.23 & 2.20 & 2.37 \\
Total & 2.82 & 2.82 & 3.12 & 3.13 & 3.20 & 3.42 & 3.46 & 3.62 \\
KP revisions & & & & & & & & \\
Male & 0.04 & 0.06 & 0.08 & 0.07 & 0.07 & 0.07 & 0.12 & 0.10 \\
Female & 0.12 & 0.10 & 0.13 & 0.12 & 0.14 & 0.18 & 0.17 & 0.21 \\
Total & 0.16 & 0.16 & 0.21 & 0.20 & 0.22 & 0.26 & 0.29 & 0.31 \\
Complications & & & & & & & & \\
Male & 0.11 & 0.13 & 0.16 & 0.15 & 0.19 & 0.20 & 0.24 & 0.27 \\
Female & 0.23 & 0.28 & 0.33 & 0.36 & 0.40 & 0.42 & 0.52 & 0.53 \\
Total & 0.34 & 0.41 & 0.49 & 0.52 & 0.59 & 0.62 & 0.76 & 0.80 \\
\hline
\end{tabular}

Abbreviations: $\mathrm{KP}=$ Knee prosthesis, $\mathrm{OA}=$ Osteoarthritis, $\mathrm{IR}=$ Incidence rate.

Conclusions: These results underscore the increasing burden associated with severe knee OA, especially in younger age categories. Improved guidelines aimed at avoiding complications and revisions are required to counteract this trend.

References:

[1] Dutch Arthroplasty Register (LROI). Arthroplasty in the Picture, Annual Report of the Dutch Arthroplasty Register. 2014.

Disclosure of Interest: None declared

DOI: 10.1136/annrheumdis-2017-eular.2101

\section{THU0604 THE ASSESSMENT OF THE DUTCH QUALITY REGISTRY RHEUMATOID ARTHRITIS QUALITY INDICATORS IN THREE PILOT HOSPITALS}

S. Mahmood $^{1}$, L. van Tuyl ${ }^{1}$, P. van Riel ${ }^{2}$, S. Rongen ${ }^{2}$, D. van Schaardenburg ${ }^{1}$, C. Allaart ${ }^{3}, R$. van den Berg ${ }^{3,4}, H$. Moens ${ }^{5}$, R. Landewé ${ }^{1}$. ${ }^{1}$ Amsterdam

Rheumatology and immunology Center, Amsterdam; ${ }^{2}$ Bernhoven, Uden; ${ }^{3}$ LUMC, Leiden; ${ }^{4}$ Erasmus MC, Rotterdam; ${ }^{5}$ Ziekenhuis Groep Twente, Almelo, Netherlands

Background: While practical guidelines and recommendations play an important role in the treatment of RA, rheumatologists often tend to deviate from these guidelines (1). This may result in disparity of quality of care among individual doctors and hospitals. To establish the best possible care, quality measures are needed. These aim to quantify the quality of the delivered care and will form the foundation of quality registries. Standardization of care processes in combination with public reporting of performance (by means of a quality registry) has been suggested to improve quality of care (2).

Objectives: To develop feasible quality indicators (QIS), endorsed by the different stakeholders of the Dutch Quality registry Rheumatoid Arthritis (DQRA).

Methods: An expert group of 8 rheumatologists, 2 patient representatives and 1 healthcare insurer representative developed a minimal set of QIs via a Delphi-like procedure (3), endorsed by the Dutch Society for Rheumatology. Since October 2015, these Qls have been registered by rheumatologists and rheumatology nurses, once a year in 26 hospitals, along with a patient evaluation questionnaire regarding the received care. To determine whether it is feasible to collect these QIs in daily practice, retrospective data from three hospitals was obtained (hospital $A$ (university), B and C (non-academic)).

Feasibility was determined by evaluation of:

1. Completeness of registered data (figure 1)

2. Possibility to calculate disease activity categories (remission, low-high disease activity)

3. Possibility to calculate changes over time in disease activity categories

4. Extraction of data regarding (b)DMARD use

Results: Selected QIs are:

1. Percentage of patients in a certain disease activity category
2. Percentage of patients using a certain (b)DMARD

3. Patient reported experience with received care

Hospital B provided only data from one year (2014) and was not able to extract data on medication from their electronic record system.

Table 1. Assessment of feasibility of the DQRA QIs

\begin{tabular}{|c|c|c|c|c|}
\hline \multicolumn{5}{|c|}{ Disease activity category } \\
\hline Indicator (DAS28) & $\begin{array}{c}\text { Hospital A } \\
(\mathrm{n}=791)\end{array}$ & $\begin{array}{c}\text { Hospital B } \\
(n=1395)\end{array}$ & $\begin{array}{c}\text { Hospital C } \\
(n=822)\end{array}$ & Mean \\
\hline Remission & $43.6 \%$ & $45.1 \%$ & $63.6 \%$ & $50.8 \%$ \\
\hline Low disease activity & $16.3 \%$ & $15.2 \%$ & $14.1 \%$ & $15.2 \%$ \\
\hline Moderate disease activity & $32.8 \%$ & $30.1 \%$ & $19.1 \%$ & $27.3 \%$ \\
\hline High disease activity & $7.3 \%$ & $9.6 \%$ & $3.2 \%$ & $6.7 \%$ \\
\hline \multicolumn{5}{|c|}{ Changes over time in disease activity categories (2014-2015) } \\
\hline Indicator (DAS28) & $\begin{array}{c}\text { Hospital A } \\
(n=415)\end{array}$ & Hospital B & $\begin{array}{c}\text { Hospital C } \\
(n=653)\end{array}$ & Mean \\
\hline Stable over time & $48.7 \%$ & N.A. & $58.8 \%$ & $53.8 \%$ \\
\hline Decreased in disease activity category & $24.8 \%$ & N.A. & $17.9 \%$ & $21.4 \%$ \\
\hline Increased in disease activity category & $26.5 \%$ & N.A. & $23.3 \%$ & $24.9 \%$ \\
\hline \multicolumn{5}{|c|}{ DMARD use } \\
\hline Indicator & $\begin{array}{c}\text { Hospital A } \\
(n=1081)\end{array}$ & Hospital B & $\begin{array}{c}\text { Hospital C } \\
(n=1105)\end{array}$ & Mean \\
\hline sDMARD monotherapy & $41.2 \%$ & N.A. & $51.6 \%$ & $46.4 \%$ \\
\hline sDMARD combination therapy & $29.4 \%$ & N.A. & $27.8 \%$ & $28.6 \%$ \\
\hline bDMARD & $29.4 \%$ & N.A. & $16.0 \%$ & $22.7 \%$ \\
\hline No DMARDs & $0 \%$ & N.A. & $4.7 \%$ & $0 \%$ \\
\hline
\end{tabular}

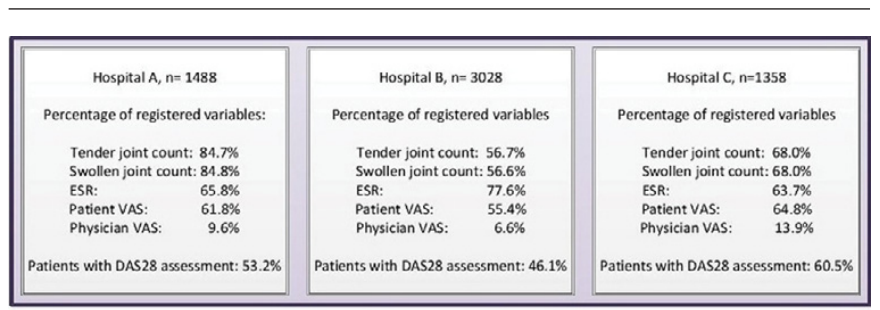

Figure 1: completeness of registered date

Conclusions: The DQRA is the first to incorporate perspectives from three stakeholders (patients, physicians and healthcare insurers) and successfully formed a limited set of QI. Collection of these indicators was feasible in two out of the three participating hospitals and offers insight in differences in provided and perceived care for RA patients.

References:

[1] Mahmood et al. Best Pract Res Clin Rheumatol 2015.

[2] Chassin et al. Health Aff 2002

[3] Mahmood et al. ARD 2016.

Disclosure of Interest: None declared

DOI: 10.1136/annrheumdis-2017-eular.1824

\section{THU0605 IMPACT OF NON-PERSISTENCE TO SUBCUTANEOUS TNF-ALPHA INHIBITORS ON MEDICAL RESOURCE UTILIZATION AND COSTS}

M. Belhassen ${ }^{1}$, F. Tubach ${ }^{2}$, C. Hudry ${ }^{3}$, M.-C. Woronoff ${ }^{4}$, L. Levy-Bachelot ${ }^{5}$, L. Lamezec ${ }^{5}$, E. Van Ganse ${ }^{1}$, B. Fautrel ${ }^{6}$. ${ }^{1}$ Hesper 7425 , Health Services and Performance Research, University Claude Bernard Lyon 1, PELyon,

Pharmacoepidemiologie Lyon, Lyon; ${ }^{2}$ APHP, Hôpital Pitié-Salpêtrière,

Département de Biostatistiques, Santé publique et Information médicale, APHP, Centre de Pharmacoépidémiologie (Cephepi); INSERM, UMR 1123 ECEVE; Université Pierre et Marie Curie Paris 6, Sorbonne Universités: ${ }^{3}$ AP-HP Hôpital Cochin, Paris; ${ }^{4} \mathrm{CHU}$ Besançon, Université Franche-Comté, Comue Ubfc, UMR INSERM 1098, Besançon; ${ }^{5}$ Merck Sharp \& Dohme, Paris, France; ${ }^{6}$ Sorbonne Universités, UPMC Univ Paris 06; AP-HP, Rheumatology Department, Pitié Salpétrière University Hospital, Paris, France., Paris, France

Background: Biotherapies such as subcutaneous tumour necrosis factor-alpha inhibitors (SC-TNFis) have transformed the management of rheumatoid diseases. The assessment of SC-TNFis non-persistence and its impact on medical resource utilization and costs are needed.

Objectives: The objective was to assess the impact of non-persistence to subcutaneous TNF-alpha inhibitors on medical resource utilization and costs, for patients initiating treatment with an SC-TNFi in France.

Methods: The Système National d'Information Inter-régime [French national health insurance scheme information-sharing system] (SNIIRAM) database lists all outpatient and inpatient healthcare consumption for individuals covered by the general health insurance scheme. Using French claims data, conditions were diagnosed using Long Term Disease status and hospital admission, based on ICD-10 codes of rheumatoid arthritis, psoriatic arthritis and ankylosing spondylitis. Patients were then identified through first-line prescription filled for adalimumab (ADA), etanercept (ETA), certolizumab pegol (CZP) and golimumab (GLM) between 2012/07/01 and 2012/12/31. 12-months persistence status was 